Artikel Penelitian

\title{
Uji Aktivitas Antioksidan Ekstrak n-Heksana, Etil Asetat, Metanol Daun dan Akar Bakau Merah (Rhyzophora stylosa) dengan Metode DPPH
}

\author{
Ahmad Hanapi, A. Ghanaim Fasya*, Abdan Syakuro
}

Jurusan Kimia, Fakultas Sains dan Teknologi, Universitas Islam Negeri Maulana Malik Ibrahim, Malang, Indonesia, 65144

\section{INFO ARTIKEL}

\section{Riwayat Artikel}

Diterima 15 Mei 2019

Direvisi 10 Juni 2019

Tersedia online 30 Agustus 2019

\footnotetext{
* Email penulis korespondensi:

fasya.organik@kim.uin-malang.ac.id
}

\section{ABSTRAK}

Red mangrove (Rhizophora stylosa) is one of the mangrove species which is abundance in the coast of Java. The mangrove contains a lot of active compounds that is potent as antioxidant. The objective of this study was to determine antioxidant activity of n-hexane, ethyl acetate, and methanol extract of red mangrove leaves and roots using DPPH (1,1-diphenyl-2-picrylhydrazyl) method. Active compound extraction of red mangrove is conducted by gradual maceration. According to phytochemical analysis, crude root extract showed the presence of flavonoids, tannins, and steroids/triterpenoids, while crude leave extract showed the presence of alkaloids, flavonoids, tannins, saponins, and steroids/triterpenoids. $\mathrm{EC}_{50}$ value of methanol extract from red mangrove leaves and roots was 5.01 and $2.55 \mathrm{ppm}$, respectively, whilst of ethyl acetate extracts from red mangrove leaves and roots was 89.94 and 8.51 ppm, respectively. Crude extract $n$-hexane has antioxidant activity 33.14 ppm $\left(E_{50}\right)$. Roots and leaves extracts have high activity of antioxidant.

Keywords: Antioxidant, red mangrove, DPPH method

Bakau merah (Rhizophora stylosa) merupakan salah satu spesies bakau yang keberadaannya sangat melimpah di pesisir pantai Pulau Jawa dan mengandung banyak senyawa aktif yang berpotensi sebagai antioksidan. Penelitian ini bertujuan untuk mengetahui aktifitas antioksidan ekstrak n-heksana, etil-asetat, metanol pada akar dan daun bakau merah menggunakan metode DPPH. Ekstraksi senyawa aktif pada akar dan daun dilakukan dengan metode maserasi bertingkat menggunakan n-heksana, etil asetat dan metanol. Ekstrak kasar dilakukan uji fitokimia dan aktivitas antioksidannya menggunakan metode DPPH (1,1-difenil-2-pikrilhidrazil). Hasil pengujian fitokimia dari ekstrak kasar akar menunjukkan adanya senyawa flavonoid, tanin, dan steroid/triterpenoid, sedangkan ekstrak kasar daun menunjukkan adanya alkaloid, flavonoid, tanin, saponin, dan steroid/triterpenoid. Nilai EC 50 (Efficient Concentration) ekstrak metanol daun dan akar berturut-turut sebesar 5,01 dan 2,55 ppm, sedangkan ekstrak etil-asetat daun dan akar berturut-turut sebesar 89,94 dan 8,51 ppm. Adapun ekstrak n-heksana daun menghasilkan nilai $\mathrm{EC}_{50}$ sebesar 33,14 ppm. Ekstrak akar dan daun bakau merah memiliki aktivitas antioksidan yang tinggi.

Kata kunci: Antioksidan, bakau merah, metode DPPH 


\section{Pendahuluan}

Indonesia memiliki ekosistem bakau (mangrove forest) yang luas yaitu $\pm 2,5$ juta ha melebihi Brazil ( $\pm 1,3$ juta ha), Nigeria $( \pm 1,1$ juta ha) dan Australia $( \pm 0,97$ juta ha) [1]. Jenis bakau yang banyak ditemukan antara lain api-api (Avicennia sp.), bakau (Rhyzophora sp.), tancang (Bruguiera sp.) dan bogem/pedada (Sonneratia sp.) [2]. Tanaman bakau yang telah lama dimanfaatkan dan dibudidayakan adalah bakau merah (Rhyzophora stylosa). Hal ini dikarenakan banyak kandungan metabolit sekunder yang bermanfaat didalamnya yang berpotensi sebagai obat. Senyawa metabolit sekunder yang ada pada bakau merah adalah asam karboksilat alifatik, asam lemak, flavoglycans, hidrokarbon, garamgaram anorganik, inositol, dan steroid [3].

Penelitian Vadlapudi dan Naidu [4] menunjukkan bahwa daun bakau api-api putih yang merupakan kerabat dekat bakau merah memiliki aktivitas antioksidan. Priyanto [5] juga mengemukakan ekstrak metanol bakau kurap (Rhizophora mucronata Lamck.) berpotensi sebagai antioksidan alami dengan nilai IC ${ }_{50}$ sebesar $0,72 \mathrm{ppm}$ dan mengandung senyawa aktif berupa flavonoid, tanin, fenol, hidrokuinon, dan saponin. Pada penelitian ini, ekstraksi senyawa aktif bakau merah dilakukan dengan maserasi bertingkat menggunakan tiga pelarut yaitu n-heksana, etil asetat, dan metanol. Hutabarat [6] menjelaskan bahwa rendemen ekstrak buah bakau merah dengan pelarut n-heksana, etil asetat, metanol berturut-turut sebesar 3,$45 ; 0,36$ dan $0,13 \%$.

Bakau merah adalah salah satu jenis bakau yang menyerap air tetapi mampu mencegah masuknya garam melalui saringan yang terdapat pada akar. Menurut Basyuni dkk. [7], senyawa triterpenoid memainkan peranan penting untuk melindungi bakau merah dari pengaruh garam. Selain itu, daun bakau merah yang menjadi tempat terjadinya fotosintesis juga mengandung banyak metabolit sekunder. Hal ini dikuatkan oleh pernyataan Hardiningtyas dkk. [8] bahwa kerabat dekat Rhyzophora yaitu bakau api-api putih mengandung steroid/triterpenoid pada daunnya. Adanya kandungan steroid/terpenoid pada bakau merah ini yang mendasari untuk dilakukan pengujian antioksidan.

Antioksidan didefinisikan sebagai suatu substansi yang dapat menunda, mencegah atau menghilangkan kerusakan oksidatif pada molekul target. Molyneux [9] mengemukakan bahwa metode uji DPPH (1,1-difenil-2-pikrilhidrazil) merupakan salah satu metode yang paling banyak digunakan untuk memperkirakan efisiensi kinerja dari substansi yang berperan sebagai antioksidan. Antioksidan berdasarkan sumbernya terdiri dari dua golongan yaitu antioksidan sintetik dan antioksidan alami yang merupakan hasil isolasi bahan alam [10].

Hutabarat [6] menyatakan ekstrak kasar etil asetat buah bakau merah memiliki $I C_{50}$ sebesar 79,71 ppm dan ekstrak metanol kulit batang Sonneratia alba (kerabat dekat Rhyzoporaceae) memiliki $I_{50}$ sebesar $12,2 \mathrm{ppm}$. Nilai aktivitas ekstrak metanol tersebut lebih tinggi dibandingkan asam askorbat (kontrol positif) dengan $\mathrm{IC}_{50}$ sebesar 17,64 ppm. Pada penelitian ini dilakukan uji aktivitas antioksidan ekstrak akar dan daun bakau merah menggunakan pelarut $n$-heksana, etil asetat dan metanol dengan metode DPPH.

\section{Bahan dan Metode}

\subsection{Bahan}

Bahan yang digunakan dalam penelitian ini adalah akar dan daun bakau merah (Rhyzophora stylosa) yand diambil dari Kawasan Ekowisata Bakau Surabaya. Bahan kimia yang digunakan diantaranya n-heksana 98\% (Merck), etil asetat p.a. (Merck), metanol 99,9\% (Merck), etanol 96\% (Merck), BHT (butil hidroksil toluena) dan DPPH (1,1-difenil-2pikrilhidrazil) (Merck).

\subsection{Uji Taksonomi}

Identifikasi sampel bakau merah dilakukan secara kualitatif dengan menggunakan kajian pustaka di Laboratorium Fisiologi tumbuhan Jurusan Biologi Universitas Islam Negeri Maulana Malik Ibrahim Malang.

\subsection{Preparasi Sampel}

Akar dan daun bakau merah sebanyak 5 kilogram dibersihkan, diiris kecil-kecil, dan dikeringkan dengan freeze dryer selama 24 jam. Sampel yang sudah kering dihaluskan hingga didapatkan serbuk akar dan daun bakau merah [11].

\subsection{Uji Kadar Air}

Sampel akar dan daun bakau merah sebanyak 5 gram dimasukkan dalam cawan porselen yang sudah diketahui berat konstannya, kemudian dioven pada suhu $100-105^{\circ} \mathrm{C}$ dan didinginkan dalam desikator. Perlakuan ini diulangi sampai berat konstan. Kadar air pada akar dan daun bakau merah ditentukan menggunakan Persamaan (1) [12].

$$
\text { Kadar air }=\frac{B-C}{B-A} \times 100 \%
$$


Dimana A adalah bobot cawan kosong, $\mathrm{B}$ adalah bobot sampel dan cawan sebelum dikeringkan, dan $\mathrm{C}$ adalah bobot sampel dan cawan yang telah dikeringkan.

\subsection{Ekstraksi Maserasi}

Sampel akar dan daun bakau merah sebanyak 50 gram diekstraksi secara maserasi bertingkat menggunakan pelarut n-heksana selama 24 jam disertai pengocokan dan penyaringan. Perbandingan antara sampel dan pelarut berbeda untuk setiap sampel, yakni 1:10 untuk sampel akar dan 1:5 untuk sampel daun. Ampas yang telah diperoleh selanjutnya dimaserasi dengan menggunakan pelarut etil asetat dengan perlakuan yang sama. Ampas hasil ekstraksi dengan etil asetat dimaserasi kembali menggunakan metanol. Ketiga filtrat yang diperoleh hasil penyaringan dipekatkan menggunakan rotary evaporator [6]. Ekstrak pekat yang diperoleh ditentukan nilai rendemennya dengan Persamaan (2).

$$
\text { Rendemen }(\%)=\frac{\text { Berat ekstrak }}{\text { Berat sampel }} \times 100 \%
$$

\subsection{Uji Fitokimia}

Uji kandungan senyawa aktif dilakukan dengan uji fitokimia. Pengujian ini dilakukan untuk mengetahui ada tidaknya komponen-komponen bioaktif yang terdapat pada ekstrak kasar akar dan daun bakau merah. Uji fitokimia dilakukan pada senyawa alkaloid, steroid/triterpenoid, flavonoid, saponin dan tanin [13].

\subsection{Uji Aktivitas Antioksidan}

Pengujian aktivitas antioksidan diawali dengan menentukan panjang gelombang maksimum. Larutan DPPH 0,1 mM sebanyak $6 \mathrm{~mL}$ didiamkan selama \pm 10 menit. Larutan kemudian ditentukan panjang gelombang maksimumnya. Nilai panjang gelombang ini akan digunakan untuk tahap selanjutnya [14].

Pengukuran aktivitas antioksidan pada semua ekstrak dilakukan dengan variasi konsentrasi $5,10,15,20,25,30$ ppm, terkecuali pada ekstrak etil asetat daun. Variasi konsentrasi ekstrak etil asetat daun adalah 1, 10, 50, 100, dan 200 ppm. Sampel sebanyak 6,75 mL dari masing-masing konsentrasi dan ditambahkan 2,25 mL DPPH 0,1 mM. Kemudian, sampel diinkubasi pada suhu $37^{\circ} \mathrm{C}$ selama 30 menit untuk selanjutnya diukur absorbansinya pada panjang gelombang maksimum. BHT digunakan sebagai kontrol positif pada penelitian ini.

Kapasitas antioksidan ditentukan menggunakan nilai $\mathrm{EC}_{50}$ (Efficient Concentration). Nilai ini menyatakan besarnya konsentrasi larutan sampel yang dibutuhkan untuk mereduksi radikal bebas DPPH sebesar 50\%. Nilai $\mathrm{EC}_{50}$ diperoleh dengan menghubungkan antara konsentrasi sampel dan aktivitas antioksidan menggunakan program GraphPad Prism 6 $[9,15,16]$.

\section{Hasil dan Pembahasan}

\subsection{Identifikasi Sampel}

Hasil identifikasi sampel menunjukkan bahwa sampel termasuk dalam golongan keluarga Rhyzoporaceae dengan spesies Rhyzophora stylosa Griff dan nama lokal bakau merah.

\subsection{Uji Kadar Air}

Kadar air bakau merah pada akar dan daun basah berturut-turut sebesar 33,81 dan $45,87 \%$, sedangkan kadar air pada akar dan daun kering berturut-turut sebesar $9,45 \%$ dan 4,27\%. Nurmillah [17] mengungkapkan kadar air maksimum untuk memenuhi syarat maserasi yaitu $<10 \%$. Sampel akar memiliki kadar air yang tinggi karena pada habitat tumbuhnya akar terendam oleh air laut sehingga banyak menyerap air daripada daun yang tumbuhnya di atas permukaan air laut.

\subsection{Ekstraksi Maserasi}

Ekstrak metanol pada akar dan daun memiliki rendemen yang paling tinggi dibandingkan ekstrak n-heksana dan etil asetat (Tabel 1). Hal ini terjadi karena senyawa metabolit sekunder berada dalam bentuk ikatan glikosida yang terikat pada gugus gula sehingga cenderung untuk bersifat polar dan lebih mudah terekstrak dalam pelarut yang bersifat polar pula.

\subsection{Uji Fitokimia Bakau Merah}

Berdasarkan uji fitokimia pada bakau merah diketahui bahwa ekstrak n-heksana daun mengandung senyawa steroid/terpenoid, sedangkan ekstrak n-heksana akar tidak dilakukan pengujian. Ekstrak etil asetat baik pada akar maupun daun masing-masing mengandung senyawa flavonoid dan steroid/terpenoid. Selain flavonoid dan 
steroid/terpenoid, ekstrak etil asetat pada daun juga mengandung tanin. Pada akar, ekstrak metanol mengandung flavonoid dan tanin, sedangkan pada daun ekstrak metanol mengandung semua metabolit sekunder yang meliputi alkaloid, flavonoid, tanin, saponin, dan steroid/terpenoid.

Tabel 1. Rendemen Ekstrak Akar dan Daun Bakau Merah

\begin{tabular}{ccc}
\hline \multirow{2}{*}{ Ekstrak } & \multicolumn{3}{c}{ Rendemen (\%) } \\
\cline { 2 - 3 } & Akar & Daun \\
\hline n-Heksana & 0,52 & 4,53 \\
Etil asetat & 1,02 & 7,09 \\
Metanol & 20,45 & 18,60 \\
\hline Perbandingan antara sampel dan pelarut untuk sampel akar adalah 1:10, sedangkan untuk
\end{tabular}
sampel daun adalah 1:5.

\subsection{Uji Aktivitas Antioksidan}

Pengujian kemampuan antioksidan ekstrak ditunjukkan dengan nilai $\mathrm{EC}_{50}$. Semakin kecil nilai $\mathrm{EC}_{50}$ maka semakin besar ekstrak bakau merah sebagai antioksidan. Gambar 1 menunjukkan bahwa ekstrak metanol pada akar dan daun menghasilkan $\mathrm{EC}_{50}$ masing-masing sebesar 2,55 dan 5,01 ppm. Nilai $\mathrm{EC}_{50}$ ekstrak etil asetat akar dan ekstrak n-heksana daun berturut-turut adalah 8,51 dan 33,14 ppm.

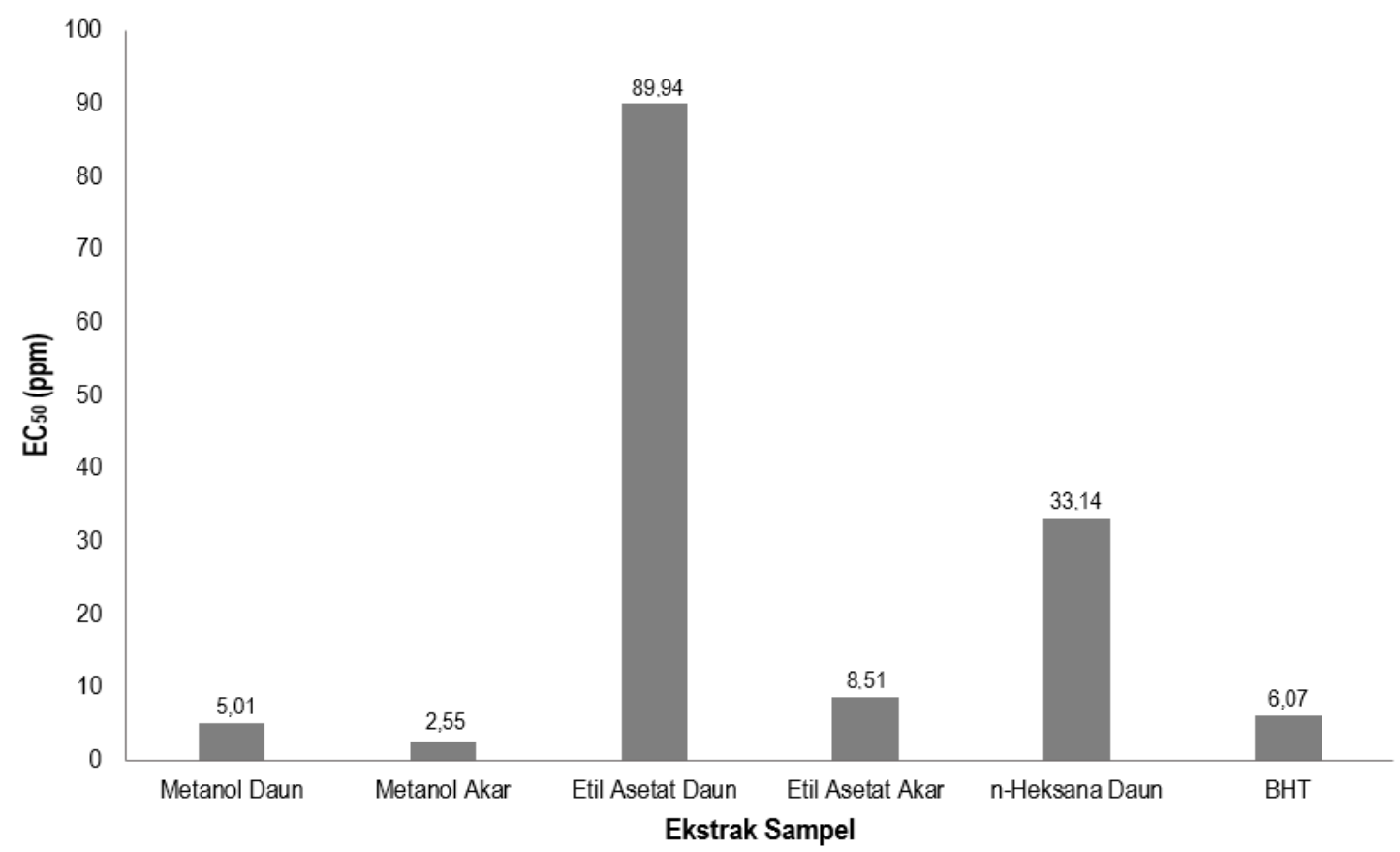

Gambar 1. Aktivitas antioksidan pada ekstrak bakau merah dan BHT yang ditunjukkan dengan nilai $\mathrm{EC}_{50}$. Panjang gelombang maksimum yang digunakan adalah $514 \mathrm{~nm}$.

Berbeda dengan ekstrak yang lainnya, ekstrak etil asetat pada daun menunjukkan nilai $\mathrm{EC}_{50}$ yang cukup tinggi yaitu 89,94 ppm. Pengujian kapasitas antioksidan tidak dilakukan pada ekstrak n-heksana akar karena jumlah ekstrak yang diperoleh sedikit. Blois [18] menyebutkan suatu ekstrak dikatakan berpotensi sangat kuat sebagai antioksidan apabila memiliki EC $C_{50}$ kurang dari 50 ppm dan berpotensi kuat sebagai antioksidan apabila memiliki EC $\mathrm{E}_{50}$ sebesar 50-100 ppm. Berdasarkan pernyataan tersebut, empat ekstrak bakau merah (ekstrak metanol daun, metanol akar, etil asetat akar dan n-heksana daun) memiliki aktivitas antioksidan yang sangat kuat.

Pengujian aktivitas antioksidan ekstrak bakau merah dibandingkan dengan BHT sebagai kontrol positif bertujuan untuk mengetahui efektifitas antioksidan alami (ekstrak bakau merah) terhadap antioksidan sintetik (BHT). Ekstrak metanol pada akar dan daun memiliki nilai $\mathrm{EC}_{50}$ yang lebih kecil dibandingkan dengan $\mathrm{BHT}$. Ekstrak bakau merah baik akar maupun daun dapat digunakan sebagai antioksidan alternatif dari bahan alam. 


\section{Kesimpulan}

Aktivitas antioksidan ekstrak metanol dan etil asetat akar bakau merah (Rhyzophora stylosa) dengan nilai $\mathrm{EC}_{50}$ berturut-turut sebesar 2,55 dan 8,51 ppm, sedangkan ekstrak metanol, etil-asetat, dan n-heksana daun berturut-turut sebesar 5,01; 89,94 dan 33,14 ppm. Berdasarkan nilai EC 50 yang diperoleh, ekstrak bakau merah berpotensi kuat sebagai antioksidan alami.

\section{Daftar Pustaka}

[1] Y. R. Noor, M. Khazali, \& I. N. N. Suryadiputra, Panduan Pengenalan Mangrove di Indonesia. Bogor: Wetlands International Indonesia Programme, 1999.

[2] D. G. Bengen, Pedoman Teknis Pengenalan dan Pengelolaan Ekosistem Mangrove Cetakan ke-2. Bogor: Pusat Kajian Sumberdaya Pesisir dan Lautan, Institut Pertanian Bogor, 2000.

[3] W. M. Bandaranayake, "Bioactivities, Bioactive Compounds and Chemical Constituents of Mangrove Plants," Wetlands Ecology and Management, vol. 10, pp. 421-452, 2002.

[4] V. Vadlapudi, \& K. C. Naidu, "Evaluation of Antioxidant Potential of Selected Mangrove Plants," Journal of Pharmacy Research, vol. 2, no. 11, pp. 1742-1745, 2009.

[5] R. A. Priyanto, "Aktivitas Antioksidan dan Komponen Bioaktif pada Buah Bakau (Rhizophora mucronata Lamk.)," Skripsi, Institut Pertanian Bogor, Bogor, 2012.

[6] R. H. Hutabarat, "Aktivitas Antihiperglikemik dan Antioksidan Buah Bakau Merah (Rhizophora stylosa Griff.)," Skripsi, Institut Pertanian Bogor, Bogor, 2014.

[7] M. Basyuni, S. Baba, Y. Kinjo, \& H. Oku, "Salinity Increases the Triterpenoid Content of a Salt Secretor and a Non Secretor Mangrove, Aquatic Botany, vol. 97, no. 1, pp. 17-23, 2012.

[8] S. D. Hardiningtyas, S. Purwaningsih, \& E. Handaryani, "Aktivitas Antioksidan dan Efek Hepatoprotektif Daun Bakau Api-Api Putih," Jurnal Pengolahan Hasil Perikanan Indonesia, vol. 17, no. 1, 2014.

[9] P. Molyneux, "The Use of the Stable Free Radical Diphenylpicrylhydrazyl (DPPH) for Estimating Antioxidant Activity," Songklanakarin Journal of Science and Technology, vol. 26, no. 2, pp. 211-219, 2003.

[10] D. Rohdiana, "Aktivitas Daya Tangkap Radikal Polifenol dalam Daun Teh", Majalah Jurnal Indonesia, vol. 12, pp. 53-58, 2001.

[11] L. E. Garcia-Amezquita, J. Welti-Chanes, F. T. Vergara-Balderas, \& D. Bermúdez-Aguirre, "Freeze-Drying: The Basic Process," Encyclopedia of Food and Health, pp. 104-109, 2016.

[12] AOAC, Official Methods of Analysis. Washington: Association of Official Analytical Chemists, 1995.

[13] J. B. Harbone, Metode Fitokimia: Penuntun Cara Modern Menganalisis Tumbuhan. Bandung: Penerbit ITB, 1987.

[14] D. Rahayu \& S. D. Hastuti, "Stabilitas Saponin Sebagai Antioksidan Alami Hasil Isolasi Gel Daun Aloe barbadensis Miller pada Variasi Suhu dan Lama Simpan," Jurnal Farmasi, vol. 1, no. 1, pp. 1-15, 2009.

[15] S. K. Bariyyah, "Uji Aktivitas Antioksidan terhadap DPPH dan Identifikasi Golongan Senyawa Aktif Ekstrak Kasar Mikroalga Chlorella sp. Hasil Kultivasi dalam Medium Ekstrak Tauge," Skripsi, Universitas Islam Negeri Maulana Malik Ibrahim, Malang, 2013.

[16] Ernawati, "Identifikasi Awal dan Uji Aktivitas Antioksidan Ekstrak Teripang Pasir (Holothuira scabra) Pesisir Pamekasan dengan Metode DPPH," Skripsi, Universitas Islam Negeri Maulana Malik Ibrahim, Malang, 2013.

[17] O. Y. Nurmillah, "Kajian Aktivitas Antioksidan dan Antimikroba Ekstrak Biji, Kulit Buah, Batang dan Daun Tanaman Jarak Pagar (Jatropha curcas L.)," Skripsi, Institut Pertanian Bogor, Bogor, 2009.

[18] S. M. Blois, "Antioxidant Determination by the Use of Stable Free Radicals," Nature, vol. 181, pp. 1199-2000, 1958. 